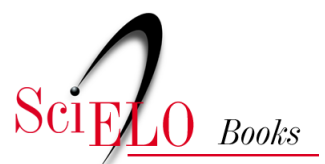

\title{
eduepb
}

\section{Desenvolvendo a Oralidade no Ensino Básico: o vídeocast em sala de aula}

\author{
Geizielle Nathália F. Athouguia \\ Luiz Francisco Dias
}

\section{SciELO Books / SciELO Livros / SciELO Libros}

ATHOUGUIA, G. N. F., and DIAS, L. F. Desenvolvendo a Oralidade no Ensino Básico: o vídeocast em sala de aula. In: ARANHA, S. D. G., and SOUZA, F. M., eds. Práticas de ensino e tecnologias digitais [online]. Campina Grande: EDUEPB, 2018, pp. 27-53. Ensino e aprendizagem collection, vol. 3. ISBN: 978-85-78795-26-9. http://doi.org/10.7476/9786586221657.0003.

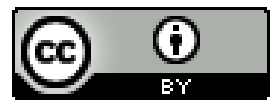

All the contents of this work, except where otherwise noted, is licensed under a Creative Commons Attribution 4.0 International license.

Todo o conteúdo deste trabalho, exceto quando houver ressalva, é publicado sob a licença Creative Commons Atribição 4.0.

Todo el contenido de esta obra, excepto donde se indique lo contrario, está bajo licencia de la licencia Creative Commons Reconocimento 4.0. 


\title{
DESENVOLVENDO A ORALIDADE NO ENSINO BÁSICO: o vídeocast em sala de aula
}

\author{
Geizielle Nathália F. Athouguia ${ }^{1}$ \\ Luiz Francisco Dias ${ }^{2}$
}

\section{Considerações iniciais}

Um dos pontos fracos do ensino de língua materna é o desenvolvimento da modalidade oral no âmbito das atividades em sala de aula. Por sua vez, a escola se ressente também da distância entre as práticas de linguagem constituídas nos espaços digitais e as práticas de linguagem escolares, muitas vezes ainda permeadas pelos modelos textuais de pouco apelo entre os jovens. Por sua vez, os espaços digitais estão carregados de práticas de linguagem atraentes para os jovens. Trata-se de textualizações próprias do espaço digital. Dentre elas, encontra-se o videocast.

1 Mestre profissional em Letras (PROFLETRAS/UFMG). Professora de Língua Portuguesa do ensino básico da rede pública de Minas Gerais.

2 Doutor em Linguística pela UNICAMP. Professor titular da UFMG. Pesquisador do CNPQ. 
Neste texto, apresentamos um trabalho desenvolvido com vistas a produzir perspectivas de abordagem desse ponto franco no ensino. Trata-se da produção de videocast em sala de aula. Trabalhamos com a tese segundo a qual o desenvolvimento da oralidade pode ser incrementado pela prática de produção de videocasts pelos próprios alunos, em contexto de uso real. Além disso, ele pode ser um bom recurso para rever pronúncia e vocabulário, como também compreensão oral. Na mesma direção, a criação desses pequenos vídeos pode ser um excelente exercício para trabalhar pontos essenciais para a apreensão da competência oral, como ritmo, junção de palavras, entonação etc.

Uma das características modernas do vídeo se configura por ele ser composto por muitas linguagens. Esse caráter "multi" do vídeo vai ao encontro da proposta de "multiletramentos" de Rojo; Moura (2012). Por sua vez, Vargas et al. (2007, p.2) afirmam que "a produção de vídeos digitais pode ser utilizada como atividade de ensino e aprendizagem com vasto potencial educacional". Isso é devido à sua dinamicidade e comum associação com o entretenimento. Nesse sentido, fica nítido que a utilização do vídeo como fonte de ensino apresenta uma considerável possibilidade de motivação e envolvimento.

Os autores pontuam, ainda, a colaboração da produção de vídeos no desenvolvimento do pensamento crítico do aluno, além da promoção da expressão e da comunicação. O uso dos vídeos permite, também, propostas interdisciplinares, pois é inegável o caráter de integração de diferentes habilidades e capacidades do aluno, através desse recurso. 
No caso da presente pesquisa, os vídeos foram utilizados para abordagem de conteúdos específicos, a saber, resenhas de livros. Nesse aspecto, a relação entre o escrito e o oral está em foco.

O mundo virtual agrega rapidamente ao cotidiano, não apenas da comunidade escolar, mas da sociedade como um todo, tipos novos de textos, sejam orais ou escritos. Marcuschi (2002, p.13) afirma que "os gêneros textuais não são instrumentos estanques e enrijecedores da ação criativa dos usuários da língua". Dessa maneira, é preciso que os alunos estejam preparados para identificar, reconhecer e entender o funcionamento desses discursos, já que há uma conexão entre contexto social, cultural, tecnológico e virtual. Essa realidade, cada vez mais tecnológica e conectada, alterou significativamente o modo de produzir informações e, com isso, temos o constante surgimento de novos gêneros textuais, constituindo o que se denomina de "e-comunicação".

Partindo desse contexto, o uso didático do celular é uma alternativa pedagógica a ser considerada, de modo a buscar a união da facilidade que os discentes possuem no trato com essa mídia e toda a riqueza de gêneros que as redes sociais possuem, por exemplo. Ter a internet como aliada no processo ensino-aprendizagem em muito pode colaborar com o amadurecimento crítico dos alunos, pois sabemos que essas redes divulgam um grande número de gêneros e de informações, e o nosso público ainda não tem preparo o suficiente para se posicionar criticamente ante ao que é amplamente difundido nesses espaços. No contexto desta pesquisa, o YouTube serviu como ferramenta didática de suma importância, pois houve, nessa utilização dos vídeos nas aulas, a possibilidade de motivar os 
alunos a produzir outros materiais. Destaca-se, aqui, o quanto isso oportunizou o desenvolvimento da expressão dos alunos

Na realidade, a escola é um lugar propício a esse exercício, tendo em vista a possibilidade de se constituir nela um espaço de formação de opinião e conceitos por parte dos alunos. Atualmente, o que temos visto é uma visão de vilania do celular por parte dos professores, mais precisamente no que diz respeito à conexão com a internet, em relação à sala de aula. Isso é compreensível, pois os recursos de mídia são muito mais atrativos para os alunos, que passam a ver, cada vez mais, as aulas tradicionais como desinteressantes e enfadonhas, o que acarreta um conflito entre os professores e seu alunado, principalmente, o adolescente.

A tecnologia deve ser uma aliada da leitura e da escrita para que transformações possam ser alcançadas. $\mathrm{O}$ trabalho com os diversos gêneros deve estar ligado à intertextualidade e ao uso da tecnologia da informação e comunicação.

Com interesse em atribuir às aulas de português uma imagem mais envolvente e moderna, é preciso propor atividades capazes de colaborar com esse objetivo. Para tal, é necessário fazer uso de gêneros textuais tradicionais e a partir deles recriar textos com aspectos de novos gêneros, constituídos, é claro, em ambientes digitais.

No caso específico dessa pesquisa, trabalhamos um gênero tradicional como ponto de partida, que é a resenha, formulada em texto escrito. A partir de resenhas de obras da escritora Lygia Bojunga, os alunos elaboraram os pequenos vídeos a serem divulgados na rede digital. Essas considerações nos orientam a pensar o vídeo como 
uma significativa ferramenta em sala de aula, por ser uma inserção de novas tecnologias da informação e comunicação na escola e agregar novos modos de leitura e escrita. Dessa forma, acreditamos que refletir, organizar, propor e aplicar uma atividade de transposição de um texto escrito em vídeo pode significar uma rica atividade intertextual, em consonância com os postulados dos documentos regulatórios do ensino no País.

O principal objetivo dessa pesquisa consiste em buscar o desenvolvimento da oralidade por meio da produção de uma resenha, a qual será transposta para um gênero intermediário, que é o roteiro, que funcionará como uma ponte para a produção do vídeo, como produção final dos alunos participantes da pesquisa.

\section{Bases estruturais da pesquisa}

Tendo em vista a necessidade de promoção de um cenário que contemple a linguagem oral em situações formais de uso, é importante buscar gêneros formais que abordem um trabalho eficaz no desenvolvimento da oralidade. Nessa direção, a pesquisa utilizou o videocast (produção final).

De modo geral, os elementos composicionais de um texto recebem uma concepção estável e assimilável. As dificuldades surgem quando há a necessidade de mudança no formato no texto de origem, como por exemplo: livros que se tornam filmes, alguns gêneros que são transformados em ilustração, músicas etc. Esse movimento é chamado de transposição de gêneros ou retextualização.

Na retextualização, é preciso verificar as características de cada gênero e estabelecer entre eles uma comparação. 
Cabe identificar se há delimitações de um dos gêneros no processo de passagem para outro gênero. Para isso, é necessário também traçar estratégias para fazer a adaptação de um texto no outro, de modo a manter um paralelo no direcionamento dos sentidos nessa transposição.

Nesta pesquisa, buscamos ampliar a competência oral dos alunos, por meio da produção de vídeo, já que, através desse suporte, é possível verificar, analisar e traçar estratégias para trabalhar os meios linguísticos, visuais e sonoros da comunicação oral. Acreditamos que, após contato com os gêneros de trabalho, participarem de oficinas que abordam as suas características composicionais, os alunos poderão realizar a transposição da resenha para o vídeo, observando a manutenção do conteúdo temático do texto original.

Vimos no uso dos vídeos um interessante recurso para abordar não somente os aspectos linguísticos da modalidade oral, mas também traços paralinguísticos comuns às manifestações orais. Assim, não estaremos apenas voltados para o vocabulário ou organização da língua. Aqui entendemos como traços paralinguísticos as expressões faciais, tom de voz e gestos, e, nesta pesquisa, interessa-nos a averiguação e busca do desenvolvimento desses traços e da modalidade oral da língua como um todo nos alunos participantes da pesquisa.

Devido à propagação e à divulgação de materiais produzidos em vídeo, da consolidação do YouTube como principal site de hospedagem de vídeos, com a crescente visibilidade dos youtubers, o trabalho com esse conteúdo midiático torna-se cada vez mais produtivo. No entanto, os videocasts, muitas vezes, são considerados apenas como a transposição de outros gêneros para o suporte digital. 
Assim, selecionamos como ferramenta para trabalhar a oralidade a produção de videocasts, seguindo os padrões de Rojo; Moura (2012, p. 19) para incluir no texto linear a indicação de um texto veiculado em um suporte midiático.

Nessa direção, Rojo; Moura (2012) afirmam que a contemporaneidade tem possibilitado o surgimento de novos textos, os quais desafiam tanto a capacidade de leitura e compreensão, quanto à adequação deles às situações sociais de que participam.

$\mathrm{O}$ acesso facilitado às tecnologias tem favorecido a difusão de ideias e pensamentos por pessoas comuns, através do compartilhamento e distribuição de arquivos pela internet. O podcast é o arquivo de áudio gravado com vistas à sua divulgação, e o videocast, a mensagem em vídeo, também destinado à difusão. Por sua vez, o termo podcasting refere-se ao ato de difundir esses áudios e/ou vídeos pela internet. Já Broadcast é um termo do inglês, que traduzido significa difundir ou radiodifundir. Ele faz referência às transmissões, sejam estas de rádio, televisão e até mesmo de alto-falantes. Foi com o surgimento do aparelho da Apple, o iPod, que possui a função de tocar sons no formato $\mathrm{mp} 3$, que houve a junção das duas palavras, iPod com broadcast, nascendo, assim, o termo podcast. Na sequência, surgiu a opção de essas mensagens serem enviadas através de arquivos de vídeo (formato $\mathrm{mp} 4$ ), o que transformou o termo podcast em um termo novo, o videocast.

$\mathrm{O}$ videocast apresenta vários aspectos positivos. Um deles é a possibilidade de compartilhar mensagens diversas para amigos e parentes, informações para funcionários, aulas complementares para alunos etc. Ele se constitui de conteúdos audiovisuais, produzidos por 
blogueiros, internautas ou webmasters, e que são produzidos e publicados esporadicamente.

Por seu turno, a expressão vlog é a abreviação de videoblog (video + blog), que diz respeito a um tipo de blog em que os vídeos são os conteúdos predominantes. O que diferencia um blog de um vlog é justamente o formato da publicação. No caso dos blogs, os conteúdos são textos e imagens, já no caso do vlog, o conteúdo são vídeos. Podemos conceituar vlog, então, como um espaço de divulgação de vídeos. A produção e a publicação dos vídeos nos vlogs costumam ser periódicas.

O site mais utilizado pelos internautas para hospedar e compartilhar vídeos é o YouTube. Para que os vídeos sejam publicados por essa plataforma, é necessário que a pessoa crie um canal no site, que funcionará como um vlog para seus vídeos. O YouTube é o site eleito para abrigar os videocasts produzidos pelos alunos participantes dessa pesquisa, no entanto, existem outras inúmeras plataformas destinadas a este fim.

Nesse sentido, o YouTube vai além da possibilidade de comunicação entre as pessoas, já que pode ser utilizado, inclusive, como uma ferramenta no processo de desenvolvimento da oralidade, por proporcionar a percepção de características e marcas linguísticas. Importante considerar que essa plataforma apresenta, para tanto, uma rica variedade de textos reais pertencentes a diversos gêneros textuais, textos estes que podem ser selecionados, analisados e trabalhados em termos da oralidade.

A resenha é o gênero fundamental desta pesquisa. Motta-Roth e Hendges (2010) argumentam que à resenha compete fornecer uma opinião crítica sobre uma determinada obra, de modo que, tanto o "resenhador" - que 
descreve e avalia uma obra a partir do conhecimento adquirido ao longo da leitura - quanto o leitor têm objetivos conexos, uma vez que o autor da resenha fornece uma visão crítica e o leitor busca tal informação.

O modelo que utilizamos foi concebido por MottaRoth (1995) para o estudo de resenhas acadêmicas. No entanto, vimos nesse modelo a possibilidade de aplicação nesta pesquisa, uma vez que as resenhas produzidas pelos alunos, a grosso modo, seguem essa sistematização. Eis o modelo apresentado pela autora:

\section{APRESENTAR O LIVRO}

Passo 1: informar o tópico geral do livro; passo 2: definir o público-alvo; passo 3: dar referências sobre o autor; passo 4: fazer generalizações; passo 5: inserir o livro na disciplina.

\section{DESCREVER O LIVRO}

Passo 6: dar uma visão geral da organização do livro; passo 7: estabelecer o tópico de cada capítulo; passo 8: citar material extratextual.

3. AVALIAR PARTES DO LIVRO

Passo 9: realçar pontos específicos

4. (NÃO) RECOMENDAR O LIVRO

Passo 10a: desqualificar/recomendar o livro e/ ou; passo 10b: recomendar o livro apesar das falhas indicadas.

Fonte: Descrição esquemática das estratégias retóricas usadas no gênero resenha, segundo Motta-Roth (1995).

A transposição da resenha do escrito para o oral é considerada uma atividade textual, porque é verificado o funcionamento dos gêneros atendo-se ao seu propósito social, tema, estrutura composicional e o estilo comuns 
a eles. A transposição é considerada também uma atividade discursiva, pois acaba por envolver questões relativas à semântica e à pragmática associadas à língua. Nesse ponto, é fundamental pontuar que há entre os domínios linguísticos, textuais e discursivos uma inter-relação. A retextualização é definida por Marcuschi (2001, p. 46) como "um processo que envolve operações complexas que interferem tanto no código como no sentido."

\section{Aspectos metodológicos}

A pesquisa aqui em foco é do tipo qualitativa. Dentre as principais características desse tipo de pesquisa, Bogdan; Biklen (1994) e Lüdke; André (1986) destacam a configuração da fonte de dados, que é o ambiente natural, e sua ferramenta principal é o próprio pesquisador. Esse método enfatiza o contato direto do pesquisador com o ambiente e com a situação que está sendo investigada e o contexto no qual se apresenta, por meio do trabalho intensivo de campo.

O desenvolvimento da pesquisa se assemelha a um funil, pois, inicialmente, existem focos muito amplos; no entanto, ao final, essas questões se tornam mais específicas. Assim, o pesquisador vai delineando melhor esses focos no decorrer da pesquisa.

A presente investigação buscou analisar os resultados das produções dos alunos participantes em todas as oficinas de produção. De modo qualitativo, levantará os resultados relativos ao desenvolvimento ou não da habilidade oral desses alunos, principalmente, por meio da comparação da produção inicial e da final. 
Tomando por objetivo a realização de um produto, as fases e os procedimentos de uma pesquisa são compreendidos por etapas que são interligadas durante todo o processo, o qual é definido pelo objeto a ser pesquisado, pela opção metodológica adequada, pela coleta e análises dos dados coletados, dentre outros aspectos que podem ser descritos com base nas fases que o constituem.

A pesquisa foi orientada pelo seguinte percurso: (a) pesquisa bibliográfica e documental; (b) constituição do grupo focal; (c) aplicação do questionário; (d) oficina de contato com os gêneros; (e) oficina de vídeo - produção inicial; (f) oficinas de produção: (1)conhecendo videocasts, (2) produção de resenha, (3) motivação de leitura, (4) produção de roteiro, (5) expressão corporal, (6) interpretação vocal, (7) produção de vídeo, (8) trabalho com os vídeos dos alunos - produção final; (g) avaliação final - entrevista semiestruturada.

Os sujeitos da pesquisa foram constituídos por um grupo de alunos do sétimo ano do Ensino Fundamental de uma escola municipal de Belo Horizonte, da região de Venda Nova. As turmas do ano/série, geralmente, são compostas por cerca de 25 alunos, nessa instituição, perfazendo um total de 75 alunos, divididos em três turmas. Dado o foco da pesquisa, dispuseram-se a participar, inicialmente, 20 alunos desse total, com média de idade variando de 12 a 13 anos. A pesquisa trabalhou com dois grupos focais compostos por dez alunos cada.

A constituição de um grupo focal envolve uma técnica de pesquisa qualitativa em que a obtenção dos dados ocorre a partir de reuniões em grupo com pessoas que representam o objeto de estudo. De acordo com Gatti (2012), o grupo focal é uma técnica que permite fazer 
emergir uma multiplicidade de pontos de vista e processos emocionais, pelo próprio contexto de interação criado, permitindo a captação de significados que, com outros meios, poderiam ser difíceis de manifestar. Os participantes selecionados devem ter alguma vivência com o tema foco para que, dessa forma, a troca de informações seja produtiva.

$\mathrm{Na}$ apresentação da produção inicial, foram fornecidas informações sobre o gênero abordado, a quem a produção será voltada (público-alvo) e o formato que a produção deverá assumir. Os conteúdos dos textos que serão produzidos também constam na etapa de apresentação da situação.

A primeira produção serviu como um diagnóstico em que são observadas e traçadas as dificuldades dos alunos em relação à oralidade. Conforme propõem Schneuwly; Dolz (2004), após a apresentação da situação, o professor deverá solicitar a primeira produção que se refere ao momento em que os alunos irão produzir o primeiro texto, um videocast. Esse servirá de base para que tanto os alunos quanto a pesquisadora situem-se quanto às representações dessa atividade.

Orientando-se pela teoria acima explicitada, elaboramos um questionário que, de fato, buscasse colaborar com a coleta dos dados referentes aos conhecimentos prévios dos alunos acerca de videocasts, de resenhas literárias, da autora Lygia Bojunga, escritora das obras que serão resenhadas pelos alunos no decorrer dessa pesquisa para criação do vídeo final, dos canais do Youtube e Booktubers.

De acordo com Schneuwly; Dolz (2004), é a produção inicial que fornece elementos para o desenvolvimento das próximas fases da sequência didática. Ela possibilita ao 
professor, através de sua observação, indicar o que deverá modular e as adaptações que se fazem necessárias, considerando as necessidades dos alunos.

\section{O videocast: processo de construção}

Descreveremos a seguir as principais oficinas realizadas, e que se constituem como partes essenciais do processo de produção dos videocasts.

Oficina "conhecendo os gêneros"

Esta oficina consistiu em colocar os alunos participantes em contato com os gêneros abordados nesta pesquisa. Nessa direção, os alunos do grupo focal foram encaminhados para o laboratório de informática da escola locus. Lá, foram orientados a entrar no site YouTube, acessar o canal "Mundo Paralelo" e "Chiclete Violeta". Esses são canais de booktubers que, com determinada frequência, apresentam vídeos com resenhas de livros, visando a motivação da leitura por parte dos seguidores e interessados de modo geral. Além das resenhas, esses canais abordam, também, temas comportamentais direcionados aos públicos adolescente e jovem e, ainda, temas relacionados aos estudos, trazendo vídeos com dicas e métodos que facilitam e orientam uma rotina de estudos mais prática e eficaz.

Nesta oficina, os 10 alunos permaneceram no laboratório em torno de uma hora e trinta minutos, onde foram orientados pela pesquisadora e pela funcionária responsável pelo laboratório de informática a acessar o site a 
digitar na janela de busca o nome de um dos canais citados acima e assistir a alguns vídeos. Os alunos, de forma livre, selecionaram as resenhas e as assistiram, com auxílio de fones de ouvido. Outra orientação repassada dizia respeito à atenção que os alunos deveriam ter não apenas às resenhas assistidas, mas também à linguagem utilizada pelos booktubers.

Após esse momento, os alunos foram encaminhados para a sala de aula e, de forma mais informal e descontraída, puderam expor suas visões e opiniões acerca dos vídeos assistidos e ouvidos, como é o caso da aluna portadora de deficiência visual. As observações foram feitas seguindo direcionamentos prévios da pesquisadora, mas houve, durante toda a conversa, a liberdade para que eles pudessem expor o que perceberam, tanto para a professora, quanto para os demais colegas.

Buscando levantar as informações que os alunos possuíam a respeito desse gênero textual, foi proposto aos alunos que produzissem um vídeo com uma resenha. Não foi exigido que o objeto resenhado fosse um livro, sendo dada, mais uma vez, a liberdade de escolha para os alunos. Houve, por parte da pesquisadora, a sugestão para que os alunos resenhassem livros, filmes, músicas ou séries.

O vídeo foi filmado pela professora pesquisadora, em sala de aula, individualmente. Anterior a esse momento, foi realizada uma conversa coletiva, na qual todos os alunos se manifestaram a respeito do objeto que seria resenhado. Nesse ponto, foi notado algo que nos chamou a atenção: o fato de que apenas as meninas optaram por resenhar livros, com exceção de uma que decidiu por uma série. Os meninos, em sua totalidade, elegeram filmes. 
Essa seleção tão distinta entre os gêneros feminino e masculino chamou a atenção de tal forma que houve a necessidade de uma intervenção, por parte da pesquisadora. Os alunos, então, foram questionados quanto à sua escolha. Cabe ressaltar que esse questionamento não teve caráter crítico; a intenção era apenas a de compreender a motivação de cada escolha.

Oficina de motivação de leitura

Este foi o momento em que houve a apresentação dos livros escolhidos para serem resenhados pelos alunos, todos eles da escritora gaúcha Lygia Bojunga: A Bolsa Amarela (2000); O sofá Estampado (1985); Tchau (1997); Livro, um encontro (1988); Retratos de Carolina (2002) e $O$ Meu Amigo Pintor (1981). Os dois grupos focais tiveram acesso a essas seis obras e após a apresentação de cada uma delas, por parte da pesquisadora, eles fizeram a escolha do título que seria lido e depois resenhado.

Como forma de motivar os participantes a ler, foi importante um ambiente favorável para a apresentação tanto da autora como de sua obra. Para isso, essa oficina foi realizada na Biblioteca da escola locus dessa pesquisa e ministrada pela bibliotecária da escola juntamente com a pesquisadora.

Inicialmente, foi realizada pelas ministrantes da oficina a leitura do capítulo inicial de cada obra. Tendo por fundamento práticas realizadas em salas de aula, no decorrer da nossa carreira docente, vemos, nessa leitura de introdução à obra, uma espécie de "aperitivo" capaz de despertar nos alunos a vontade de conhecer a obra como um todo, motivando-os a realizar a leitura necessária 
para o prosseguimento dessa pesquisa. Trata-se de um momento de degustação, onde há a realização de leituras em voz alta e com entonação adequada, de trechos da obra, visando aguçar a curiosidade dos alunos em torno do livro que a ser lido.

\section{Oficina de produção de roteiro}

Esse é momento da escrita do roteiro do vídeo. Caber frisar que o videocast possui a capacidade de abordar textos com estruturas dinâmicas e ágeis. Considerando isso, cada grupo iniciou a organização de suas exposições, sempre se pautando pela estrutura e pelos elementos do produto em questão: o videocast.

De acordo com o dicionário de comunicação, o roteiro é "o texto que indica previamente o desenvolvimento de um programa de rádio ou de TV." (RABAÇA; BARBOSA, 2001, p. 651). Além disso, os autores indicam a apreensão do conceito de script, qual seja: "texto dos diálogos das narrativas e das indicações cênicas (rubricas) de programas de televisão ou rádio, filmes ou espetáculos teatrais. (RABAÇA; BARBOSA: 2001, p. 661). Foi possível extender esse conceito para o contexto dessa pesquisa. Assim, podemos afirmar que também para se produzir um vídeo é necessário que seja elaborado um roteiro que indique os pontos e o percurso por meio do qual a apresentação deverá se orientar.

Essa oficina foi ministrada pela pesquisadora e abordou pontos referentes à estrutura do gênero roteiro e alguns itens que dizem respeito ao conteúdo desse gênero, como, por exemplo: O que será apresentado? Qual o tempo de 
apresentação? Qual meu público? Qual meu objetivo com essa apresentação?

\section{Oficina de expressão corporal}

Partimos do pressuposto de que a oralidade contempla operações linguísticas complexas, como gestos, entonação, postura e expressões faciais. E tendo em vista que, na produção dos videocasts, os alunos se utilizam de todos esses recursos extralinguísticos, apreendemos a necessidade de que uma das oficinas de produção fosse voltada para a expressão corporal.

Essa oficina foi ministrada por uma profissional da área de locução e foi acompanhada pela pesquisadora. Nela, foram abordados os pontos mais importantes de uma apresentação oral, tais como: script, voz, vocabulário, expressão corporal, seleção, naturalidade, emoção e conhecimento. Cada um dos itens foi tratado pela profissional, que utilizou de uma linguagem bem acessível para alcançar os participantes.

No que diz respeito à locução, foram realizados exercícios, em dupla, nos quais os alunos precisavam realizar a leitura de sequências de palavras que possuíam os mesmos dígrafos ou terminações ou encontros vocálicos. Cada dupla recebeu uma lista, os alunos fizeram a leitura em voz baixa, entre eles; em seguida, se apresentaram para os presentes. Sob a supervisão da profissional, os alunos realizaram a leitura dos blocos de palavras, pautando-se pelas indicações feitas pela ministrante. As orientações dela baseavam-se, principalmente, no tom de voz ideal, na velocidade da fala, na postura e na gesticulação. Em todo o tempo, ela reforçou a necessidade de haver limpidez na 
fala, visando o maior e melhor entendimento do público, explicando que uma fala acelerada é pouco compreendida, e que o contrário torna a apresentação cansativa.

Em diversas etapas da aplicação dessa pesquisa, foi trabalhada com os participantes a necessidade de se haver uma preparação prévia à apresentação oral. Por isso, a proposta de uma oficina voltada ao planejamento do que seria apresentado. Essa oficina foi ministrada pela pesquisadora. Nela, foi abordado o conceito do gênero roteiro e todas as suas características.

\section{Oficina de interpretação vocal}

É de suma importância que os professores exponham seus alunos às mais diversas situações de uso da modalidade oral da língua. Marcuschi (2003, p. 14) afirma que "a conversação é a primeira das formas de linguagem a que estamos expostos e provavelmente a única da qual nunca abdicamos pela vida afora.". A linguagem oral abarca diversos recursos linguísticos e expressivos.

Buscando o desenvolvimento de alguns desses recursos, a realização dessa oficina se mostrou necessária para que os participantes alcançassem um nível de oralidade o mais claro possível, considerando, obviamente, o nível apontado na produção inicial de cada um. A oficina teve por objetivo um melhor aproveitamento da entonação vocal, a observação da necessidade das pausas corretas, o uso ou eliminação de algumas expressões, formas de evitar certos tiques orais etc.

Essa oficina foi ministrada por uma locutora de rádio e também aconteceu na escola locus dessa pesquisa. 
Oficina de produção de vídeo

Como parte dessa oficina, foi realizada uma visita dos participantes a uma escola de Youtubers, em Belo Horizonte, onde se ensina a desenvolver o processo criativo e são fornecidas informações a respeito de como abrir um canal no YouTube, por exemplo.

Vale ressaltar que, nessa etapa, foi importante que os programas de edição utilizados na realização dos videocasts já tivessem sido pesquisados e que os alunos já tivessem contato com alguns canais dos chamados "Booktubers". Esse termo faz referência às pessoas que se dedicam a fazer resenhas de livros impressos, em vídeos e as disponibiliza na internet.

É aqui que demos início aos ensaios das gravações da produção final, com apoio de celulares e tablets. Intencionalmente, a pesquisadora permitiu que os estudantes observassem que algumas das passagens do roteiro não faziam parte da dinâmica do videocast. Essas observações, feitas por eles mesmos, os fizeram perceber a necessidade de readequação do texto e refacção desses textos escritos.

Como essa etapa envolvia as gravações, todo o equipamento necessário para que os alunos pudessem trabalhar estava ao alcance deles. Porém, foi essencial estipular o tempo máximo de cada gravação, já que videocasts são vídeos curtos.

Após a gravação dos vídeos, a pesquisadora fez a análise e a seleção do material produzido. Depois da seleção dos vídeos, foi o momento de partir para as oficinas de edição. Nessas oficinas, tivemos o apoio do agente de informática da escola locus da pesquisa. Contudo, vale 
enfatizar que o trabalho foi realizado pelos próprios alunos, uma vez que vimos nessa pesquisa uma possibilidade de abordagem do letramento digital.

Trabalho com os vídeos dos alunos - produção final

Seguindo os pressupostos de Schneuwly; Dolz (2004), e finalizados todos os módulos da sequência didática abordados aqui como oficinas de produção, pudemos entender que o aluno teve a possibilidade de colocar em prática as noções e os instrumentos elaborados separadamente nos módulos. Essa produção permitiu, ainda, que a pesquisadora realizasse uma avaliação somativa. Nessa etapa, foi possível, e era esperado, que houvesse o investimento das aprendizagens. Para tanto, sugerimos que o professor, nesse momento, retome com os alunos os objetivos a serem atingidos com essa produção e ofereça a eles um controle sobre seu próprio processo de aprendizagem.

Após a produção dos vídeos, a pesquisadora fez a seleção e a análise do material produzido. Uma vez concluído esse trabalho, partimos para a abertura do canal do YouTube que hospedou os videocasts de resenhas literárias produzidas pelos alunos. Posteriormente, o canal foi divulgado ao conjunto maior de alunos e a toda a comunidade escolar, a fim de promover uma ação multiplicadora e motivadora. 


\section{A produção do videocast na escola: avaliando os resultados}

Para que a produção final tivesse um resultado de qualidade, foi importante fazer uma análise do conteúdo e dar novas orientações à turma ao fim de cada uma das etapas, lembrando que a avaliação deve estar presente em todas as oficinas de produção no decorrer da pesquisa. Para isso, a pesquisadora avaliava o material coletado e fazia a seleção de informações, além de pedir a readequação e refacção das mesmas para os alunos, se fosse o caso. As ações que percorreram essa etapa foram: leitura, reflexão com a turma acerca dos roteiros elaborados, além da observação das propostas no que se refere ao atendimento ao formato escolhido. A análise das conclusões dos estudantes sobre os trechos que precisaram ser adaptados, diferenciando, assim, texto oral e texto escrito, fizeram, também, parte da avaliação.

Como avaliação final, a pesquisadora utilizou a entrevista semiestruturada. A entrevista pode ser um rico meio de comunicação. Ela representa um instrumento básico para esse tipo de pesquisa. A entrevista consiste, basicamente, em uma conversa a dois, feita por iniciativa do entrevistador/pesquisador e é destinada a fornecer informações pertinentes para objeto de pesquisa, nesse caso, para avaliação dos resultados; ou seja, intencionalmente o pesquisador recolhe informações através da fala dos sujeitos. (LUDKE; ANDRÉ, 1986).

Inicialmente, notamos certa familiaridade dos alunos com gêneros da categoria oral, já que todos se mostraram cientes do que deveriam fazer, seja considerando 
as apresentações orais escolares ou pautando-se pelos vídeos dos booktubers assistidos na oficina "Conhecendo os gêneros".

Obviamente que fatores como timidez e insegurança foram facilmente observados, tanto na gravação do vídeo de cada um dos alunos, quanto na análise desses pela pesquisadora. A maioria dos alunos mostrou certo desconcerto ao se verem diante da câmera. No entanto, um deles teve, nitidamente, uma dificuldade muito maior em relação aos demais.

Essa fase foi de suma importância para verificar qual estava sendo a postura dos participantes diante da leitura. O processo dessa fase da oficina foi realizado através de perguntas sobre as obras direcionadas aos alunos. Como uma mesma obra foi lida por participantes diferentes, as impressões e pontos de vista dos alunos foram bastante distintos. Possivelmente essa ocorrência se deva aos conhecimentos prévios e experiências de cada um. Aproveitando a exposição de cada aluno a respeito do livro, a pesquisadora passou a mediar uma discussão entre os leitores da mesma obra com a intenção de favorecer a troca de informações, visões, conclusões acerca do livro, entre eles. Um ponto negativo dessa fase foi o fato de cinco alunos não terem avançado muito na leitura, $\mathrm{o}$ que fez com as discussões não os contemplasse de modo tão significativo.

O segundo encontro para tratar das atividades da etapa durante a leitura foi ainda mais produtiva, já que apenas dois alunos não haviam concluído a leitura, e todos os demais já chegaram expondo suas opiniões sobre as obras. Com toda a história em mente, eles tiveram mais firmeza e segurança para apresentar suas conclusões de 
leitura. Boa parte dos alunos se manifestou favorável às histórias, o que indica, ao menos aparentemente, que as obras agradaram aos alunos, salvo três deles, sendo dois que afirmaram não terem gostado e um que alegou ter gostado em partes. Aos alunos que não haviam finalizado a leitura, foi estipulado novo prazo, que foi cumprido.

As exposições dos alunos nas duas fases "durante a leitura" nos mostraram que houve mudança no modo como eles encararam o ato de ler propriamente dito e como viram as obras em si, uma vez que fizeram observações bem além do esperado. Esse encontro que havia sido, a priori, planejado para abranger algumas atividades da etapa "durante a leitura", por fim, acabou assumindo algumas atividades da etapa "depois da leitura", já que a maioria dos alunos já tinha finalizado a tarefa. As atividades desenvolvidas nessa fase foram a construção da síntese semântica do texto, a troca de impressões a respeito do texto lido e a avaliação crítica do texto.

Quanto à resenha, na produção inicial, foi observado que parte dos alunos não cumpriram um requisito básico do gênero, ou seja, não realizaram uma crítica ao objeto resenhado, o que não ocorreu na resenha apresentada no videocast final. Todos os alunos, sem exceção, expuseram seu ponto de vista a respeito do livro lido, sendo que grande parte deles optou por colocar sua opinião ao final da apresentação das partes principais do enredo.

No que se refere ao videocast, a postura dos participantes nesse item também foi um ponto de evolução, no entanto, em menor escala. De modo geral, houve melhora, mas ainda foi possível observar menos desenvoltura, diante da câmera, em pelo menos metade dos alunos. Obviamente, consideramos que essa necessidade 
de desenvoltura ante à câmera, tendo em mente a necessidade de adaptação ao local de circulação, o público-alvo e os objetivos do vídeo, trouxe uma dificuldade maior para os alunos.

Com relação à oralidade, foi possível observar melhora em muitos aspectos e na maioria dos alunos. É importante relembrar que os "aspectos extralinguísticos" foram traçados considerando uma situação comunicativa realizada pessoalmente, no entanto, entendemos que serve de parâmetro de análise na produção realizada no decorrer da aplicação dessa pesquisa. Um ponto essencial nessa análise foi o método utilizado: consideramos a avaliação do aluno em relação a ele mesmo, ou seja, nossa avaliação foi pautada na comparação da produção final com a inicial de cada aluno.

\section{Considerações finais}

Através dessa pesquisa, percebemos o valor social das interações orais, considerando os avanços comunicativos dos participantes da fase de aplicação. Reiteramos a necessidade de mudanças nas metodologias de ensino utilizadas pelas instituições escolares, no sentido de assumir e sistematizar o ensino com práticas que busquem o desenvolvimento da competência comunicativa oral.

Observamos que, ao transpor suas resenhas para videocast, os alunos aprendem não só o conteúdo, mas também são direcionados rumo a uma maior autonomia e segurança na produção textual. $\mathrm{O}$ que temos aqui é uma oportunidade de agregar as tecnologias atuais à prática docente. 
O ato de discursar/falar em público ou diante de uma câmera apresentou um desafio por colocar os sujeitos em evidência. Uma das metas dessa pesquisa foi a de buscar a capacidade de superação desse desafio por parte dos participantes. Outro ponto significativo desse trabalho foi seu fim multiplicador, ou seja, através dos videocasts com resenha, é possível despertar o desejo de outras pessoas lerem livros ou de também produzirem seus textos. Por isso, percebemos que é necessário realizar uma reflexão a respeito de possíveis formas de operacionalizar a abordagem da modalidade oral da língua, a qual compôs o eixo norteador dessa pesquisa.

Observamos que a prática da oralidade na sala de aula capacita os alunos a assumir um papel mais ativo e mais protagonista no processo de ensino/aprendizagem, tornando-os verdadeiros agentes na construção do seu próprio conhecimento, resultando, também, no desenvolvimento da sua visão crítica. Nesse sentido, não é mais possível abrir mão de reservar para garantir à modalidade oral seu lugar nas aulas de língua portuguesa (e não só delas), com vistas a preparar os alunos para diversas situações comunicativas.

Na busca por tornar o processo de ensino de linguagem mais atraente e significativa, é essencial pensar em propostas didáticas que aproximem o aluno de sua realidade, que sejam adaptadas às exigências dessa nossa sociedade cada vez mais conectada. Há uma clara possibilidade de tornar as aulas de português cada vez mais plurais e interdisciplinares lançando mão de novas tecnologias. 


\section{Bibliografia}

BOGDAN, R. C.; BIKLEN, S. K. Investigação qualitativa em educação. Porto: Porto Editora, 1994.

GATTI, B. Grupo focal na pesquisa em ciências sociais e humanas. Brasília: Líber Livro, 2012.

LÜDKE, M.; ANDRÉ, M. E. D. A. Pesquisa em educação: abordagens qualitativas. São Paulo: EPU, 1986.

MARCUSCHI, L. A. Da fala para a escrita: Atividades de retextualização. São Paulo: Cortez, 2001.

. Gêneros textuais: definição e funcionalidade. In: A.P. DIONÍSIO; A.R. MACHADO; M.A. BEZERRA (eds.). Gêneros textuais e ensino. Rio de Janeiro, Lucerna, 2002.

Análise da conversação. 5.ed. São Paulo: Ática, 2003.

MOTTA-ROTH, D. Rhetorical features and disciplinary cultures: a genre- based study of academic book reviews in linguistics, chemistry and economics. 1995. Tese (Doutorado em Linguística) - Universidade Federal de Santa Catarina, Florianópolis, 1995.

MOTTA-ROTH, D.; HENDGES, G. R. Produção textual na Universidade. São Paulo: Parábola, 2010.

RABAÇA, C. A.; BARBOSA, G. G. Dicionário de Comunicação. Rio de Janeiro. Campus, 2001.

ROJO, R; MOURA, E. Multiletramentos na escola. São Paulo, Parábola Editorial, 2012. 
SCHNEUWLY, B.; DOLZ, J. Gêneros orais e escritos na escola. Campinas: Mercado de Letras, 2004.

VARGAS et al. Promídia: produção de vídeos digitais no contexto educacional. Instituto de Computação Universidade Estadual de Campinas, Campinas - SP, 2007. Disponível em: <http://www.cinted.ufrgs.br/ ciclo10/artigos/1bAriel.pdf>. Acesso em: 13 set. 2017. 